\title{
Rádio-Acontecimento: Modos de Comunicar Potência Mental ${ }^{1}$
}

\author{
Fernanda Fontana STREPPEL ${ }^{2}$, Deisimer GORCZEVSKI ${ }^{3}$ Analice de Lima \\ PALOMBINI $^{4}$
}

\section{Resumo}

No contexto atual, parece indispensável refletir sobre a forte presença das tecnologias de comunicação em nossas vidas. Estamos todos implicados nas lógicas midiáticas que oferecem, disputam e negociam visibilidades e enunciabilidades no cenário contemporâneo. Nesse sentido, para este debate, foram destacados alguns aspectos pertinentes à mídia, no que se refere aos seus diálogos com as intervenções em rádio comunitária e aspectos relativos à saúde mental. Os sujeitos implicados nesse estudo são “loucutores” do Coletivo de Rádio Potência Mental, um grupo que produz programas de rádio. Enfatiza-se a análise dos encontros semanais de preparação e a realização dos programas. Problematiza-se o desejo de comunicar diferentes modos de fazer-se enunciar a loucura e, através dela, outros sentidos que surgem como efeito de improvisos e imprevistos no acontecimento (esquizo)radiofônico.

\section{Palavras-chave}

Tecnologias de comunicação; saúde mental; rádio; desejo; acontecimento.

\footnotetext{
Abstract

Within the current context, it seems essential to reflect about the strong presence of communication technologies in our lives. All of us are involved with these media logics that offer, fight for, and negotiate visibilities and the ability to enunciate in the contemporary scenario. In that sense, in order to set the debate, we highlighted some aspects related to the media in terms of its connection to interventions in community radio stations, as well as aspects linked to mental health. The subjects that participated

${ }^{1}$ Versão ampliada do trabalho apresentado no XV Encontro Nacional da Associação Brasileira de Psicologia Social. 2009, na Mesa Redonda: “Tecnologias de comunicação, comunidade e saúde mental”, sob o título "Entre improvisos e imprevistos: os modos de comunicar potência mental”.

${ }^{2}$ Mestranda do Curso de Pós-Graduação em Psicologia Social e Institucional - PPGPSI-UFRGS

${ }^{3}$ Docente do Instituto de Cultura e Arte da UFC, doutora em Ciências da Comunicação

${ }^{4}$ Docente do Instituto de Psicologia UFRGS, doutora em Saúde Coletiva UERJ
} 
in the present study are "crazy radio announcers" of the Radio Collective "Potência Mental", a group that produces radio shows. The analysis of the weekly meetings for the production and broadcast of the radio shows is emphasized. We analyzed the desire of communicating different ways of enunciating madness and, through madness, communicating other meanings created as a result of impromptus and mischances in the (schizo)radiocasting event.

\section{Keywords}

Communication technologies; mental health; radio; desire; event.

\section{Início de conversa}

Este trabalho parte do nosso compromisso com o campo da saúde mental, na perspectiva de um cuidado em liberdade, implicando a defesa do direito, aos que chamamos diagnosticados5 (pessoas com diagnóstico psiquiátrico), de habitar a cidade (ocupar as suas ondas sonoras, fazendo rádio, é uma das formas de habitá-la). Assim, a consolidação de serviços de saúde mental territorializados e abertos, com foco nas possibilidades de vida e não na doença, articulados em redes intersetoriais e com os atores sociais presentes no território, é um dos desafios que se apresentam aos seus profissionais, cuja formação, via de regra, vê-se circunscrita à área técnica da saúde. É um desafio, também, a todos os cidadãos, seus usuários por direito, que, de modo geral, não têm acesso à informação, ao conhecimento que lhes permita reconhecer e reivindicar outro modelo de atenção à saúde para além do hospital e da farmácia.

Buscamos, na comunicação social, canais de expressão para esses temas, entendendo as tecnologias de comunicação e, em especial, a radiodifusão, como dispositivo estratégico em que se alinham a produção de conhecimento e os movimentos de luta por uma sociedade sem manicômios à produção de conhecimento e luta pela democratização dos meios de comunicação. Assim, que a loucura possa tomar a palavra através da rádio aponta na direção de um alargamento nos modos de habitar a cidade, favorecendo os processos inclusivos. Nesse processo, onde as tecnologias de comunicação passam a ser um importante intercessor de um tipo de inserção social, as mídias comunitárias

\footnotetext{
${ }^{5}$ Este termo é tomado de empréstimo da Rádio Nikosia, de Barcelona/Espanha.
} 
assumem papel estratégico junto aos movimentos de minorias. No tocante à radiodifusão, se as rádios comunitárias têm sido marcadas pela tendência a operar no âmbito de “micropolíticas identitárias e reivindicatórias de setores sociais específicos” (COGO, 2004, p. 45), observa-se a presença de práticas que se pretendem de resistência atuando na via da desterritorialização - vide as ações das rádios livres intervindo com ou sem “permissão”.

A experiência aqui tematizada diz respeito aos encontros de produção, realização e análise posterior de programas radiofônicos por parte do Coletivo de Rádio Potência Mental, na Rádio Comunitária Lomba do Pinheiro, situada na periferia sul da cidade de Porto Alegre. Na freqüência FM 87.9, a Rádio sintoniza uma programação que acontece das 7hs às 23hs, diariamente. Com a participação de dezesseis moradores comunicadores que realizam trabalho comunitário não remunerado - a grade de programação é composta por programas musicais, informativos, de entretenimento, religiosos, entre outras temáticas e modalidades radiofônicas. É no programa “Comunidade em Ação” que acontece a intervenção do "Potência Mental em Ação”, denominação da janela que vai ao ar quinzenalmente, nas sextas-feiras das $10 \mathrm{hs}$ às 10h30min.

\section{Coletivo de Rádio Potência Mental}

O Coletivo de Rádio Potência Mental surgiu em 2006 através da iniciativa de um grupo de residentes em Saúde Mental Coletiva, inspirado na experiência realizada pela Rádio Nikosia, de Barcelona/Espanha. O nome com que o Coletivo se apresenta, Potência Mental, foi sugerido por uma ouvinte da rádio comunitária para designar os programas levados ao ar pelo grupo, sendo encampado como seu nome próprio. Assim como a Rádio Nikosia, o Potência Mental tem existência fora do contexto institucional dos serviços de saúde mental de onde provêm os diagnosticados que dele participam, o que possibilita maior fluidez e horizontalidade nas relações entre os integrantes do grupo (PALOMBINI, CABRAL, BELLOC, 2008). Como coletivo de trabalho, tanto esses diagnosticados, como os trabalhadores ou os estudantes nele incluídos, todos se vêem diante da tarefa comum de aprender e exercitar a técnica de radiodifusão; e a cada um é dada a possibilidade de experimentação de novos lugares sociais: entrevistadores, 
poetas, radialistas, cantores... (TIBULO, ROSS, NUNES et alli, 2006). Todos se fazem, no Coletivo, loucutores6 de rádio.

Ao pensar a técnica como constituinte do fazer-se loucutor, o Coletivo recusa as simplificações que a consideram dissociada do devir humano, de seu processo de invenção na interação com as coisas vivas ou não vivas de seu contexto. Nesse sentido, o Coletivo aproxima-se da compreensão de Levy (1993) quando considera que “os coletivos cosmopolitas compostos de indivíduos, instituições e técnicas não são somente meios ou ambientes para o pensamento, mas sim seus verdadeiros sujeitos” (p. 19).

Além dos programas de rádio, o grupo tem também participação em eventos diversos, como o encontro do Mental Tchê, em São Lourenço do Sul, em 2007 e 2008, onde, junto com outros grupos, ocupou-se da produção da Rádio A Voz do Poste; esteve presente no Encontro Mundial de Rádios na Saúde Mental, no ano de 2007, em Buenos Aires; participou, como palestrante convidado, do seminário sobre Mídia e Saúde Mental, na Escola de Saúde Pública do RS, em 2008, e de roda de conversa sobre o mesmo tema no Encontro Estadual de Saúde Mental do RS, em 2009, ano em que esteve presente também na Mostra do $9^{\circ}$. Salão de Extensão da Universidade Federal do Rio Grande do Sul; no ano de 2010, compartilhou programas online com a Radio Nikosia, de Barcelona e coordenou uma oficina de rádio junto aos usuários da Geração POA, serviço de geração de renda da Secretaria Municipal da Saúde de Porto Alegre.

Desde 2008, o projeto passou a contar também com a participação de estudantes e profissionais da área da comunicação, dando ênfase ao caráter interdisciplinar comunicacional, cultural e político - da proposta de produção de intervenções sonoras na cidade, mantendo-se em diálogo com as comunidades locais, não apenas sobre a saúde mental, mas sobre formas de encarar a vida e seus transbordamentos (CECCHIN, 2008). Entre os temas debatidos ressalta-se: amizade, juventude e velhice, discosvoadores, flores, teatro e prostituição.

Os participantes do Coletivo reúnem-se semanalmente para preparação dos programas na rádio que são, atualmente, quinzenais. Privilegia-se, nesses encontros, o tempo das conversações, mantendo a possibilidade, durante a semana, de iniciativas individuais ou coletivas para estudo e pesquisa de informações sobre as temáticas escolhidas, bem como o planejamento de outras atividades, produção de novas vinhetas, etc. A cada

\footnotetext{
${ }^{6}$ O termo “loucutores” foi cunhado pela Rádio Tam Tam, de Santos/Brasil, e também é utilizado pela Rádio Maluco Beleza, de Campinas/Brasil. No nosso caso, refere-se a todos os participantes, diagnosticados ou não.
} 
encontro do Coletivo, um de seus participantes fica encarregado de produzir um relato escrito da reunião. São relatos que, juntos, vão constituindo uma memória coletiva do grupo.

Dois importantes marcos de 2009 são a premiação no Concurso Público Cultural Loucos pela Diversidade do Ministério da Cultura e Escola Nacional de Saúde Pública/Fundação Oswaldo Cruz e a obtenção de recursos através do Edital PROEXT 2009 - Programa de Extensão Universitária do Ministério da Educação/Secretaria de Educação Superior, via “Rede de Oficinandos”, Programa de extensão que o Coletivo Potência Mental compõe com mais outras duas ações vinculadas à Universidade Federal do Rio Grande do Sul (uma de informática e outra de vídeo).. Essas três ações têm como objetivo comum criar, consolidar e articular modos de inserção de tecnologias da informação e comunicação - TIC - no campo da reforma psiquiátrica, no dentro/fora dos serviços de atenção à saúde mental, acompanhando seus efeitos na constituição desses espaços e nos processos de vida de seus participantes.

\section{O desejo de fazer acontecer rádio e comunicar diferença}

Tomamos como norteadoras da escrita deste artigo duas idéias: a da rádio como acontecimento, resultante da potência dos imprevistos e improvisos que emergem do seu fazer; e a do desejo de comunicar outros modos de produzir sentido e fazer-se ver e enunciar pela loucura como o que move o fazer rádio. O acontecimento, na definição de Rajchman (1991), diz respeito ao singular, inatributável ou imprevisível, implicando uma outra lógica de sentido, em que as dissonâncias levam a uma transformação, ou seja, acontecimento como distanciamento de si, ato de diferenciação - e não identificação que se repete sem diferença; já a acepção de “desejo” é referida na perspectiva que nos apontam Deleuze e Guattari (2004), ou seja, desejo como produtor de mundos. A palavra produção toma aqui seu sentido mais "forte", aquele de “produção de produção” que, portanto, renuncia à reprodução e se exprime através do paradoxo da anti-produção como produção que desorganiza para reorganizar, ou, antes, para viver na mais tênue linha habitável entre o caos e o "feito". É a produção de produção desde a desordem, tal como aprendemos com o inconsciente e com a loucura (DELEUZE E GUATTARI, 2004; 2006). É o que nos leva a experimentar o estatuto de diagnosticados para nomear as pessoas com histórico de sofrimento psíquico e inserção 
nas tramas dos serviços de saúde mental, enquanto a loucura é transposta ao Coletivo e sua produção (esquizo)radiofônica.

No fazer Potência Mental, as reuniões de preparação dos programas são tomadas de um burburinho de múltiplas conversas, afecções, pensamentos, percepções e escritos desconexos, paralelos, simultâneos, compondo um espaço de afetações, embrião da expressão. Algo se passa entre os loucutores, intensidades que podem ser da ordem de fenômenos físicos, políticos, afetivos.... Algo da desordem do desejo passa entre os loucutores e passa também entre eles e o Coletivo no qual atuam, a que constituem e pelo qual se formam, nas alianças por eles construídas e desconstruídas, bem como nas ondas sonoras que irradiam suas vozes.

Eis que intervém o programa de rádio. Trinta minutos imersos na imprevisibilidade, mediante a qual, do acontecimento-rádio, excede o sentido, jorrando singularidades nas ondas sonoras - freqüência 87.9 FM, pelas estradas do vento. É quando uma “comunicação da diferença” (CAIAFA, 2004) pode acontecer.

No texto “A escrita do acontecimento”, Barthes (2008) propõe pensar o que haveria de ser escrever um acontecimento. O autor relata a poligrafia do revolucionário Maio de 68 e conta como o rádio tornou-se ativo produtor do movimento, fornecendo e proliferando sentidos simultaneamente aos combates nas ruas e surtindo sempre novos efeitos na revolução. Desfazendo a tradicional distância entre o ato e o discurso, a rádio "era o próprio acontecimento” (p. 214).

Escrever e ser o próprio acontecimento coincidem à medida que a escrita remete aqui a uma violenta arranhadura, para além da dicotomia fala/escrita, como um ato de criação e ruptura, uma espécie de linha de fuga que inscreve novas relações para além de si mesma, o que a aproxima ao acontecimento deleuziano7. Antes de tudo, essa escrita é uma marca, uma invenção que se registra, como a defesa que Foucault (2009) faz acerca do discurso, identificando-o a uma violência que se faz às coisas, porque se trata de uma prática e não simples representação do mundo das coisas.

O discurso como prática remete-nos aos agenciamentos coletivos de enunciação delineados por Deleuze e Guattari (1995), que fazem redundar discurso e ato. Quando

\footnotetext{
${ }^{7}$ Em Deleuze (2007), o acontecimento é justamente algo no que acontece, é o expresso do acidente que acomete as coisas e os corpos, é o que resta para além da efetuação cuja grandeza é justamente o sentido. É um incorporal, constituído de singularidades liberadas dos limites da sua atualização corporal.
} 
um ou mais loucutores dizem do desejo de comunicar potência mental, estão construindo agenciamentos que são sempre coletivos - "multiplicidade que se desenvolve para além do indivíduo, junto ao socius, assim como aquém da pessoa, junto a intensidades pré-verbais” (GUATTARI, 1992, p. 20), atravessada por singularidades impessoais que determinam os termos da ação da linguagem que emerge como efeito.

Para além de representar, a linguagem age. Pelos atos ilocutórios que sempre carrega, ela agencia transformações incorpóreas que dizem as misturas dos corpos. Não fala sobre elas, mas, pela sua dimensão de ato, exatamente diz os estados de coisas, antecipa, retrocede, destaca, une, recorta as coisas. Assim, os atos iloucutórios agenciados no comunicar potência mental são intervenções; não representam as coisas, mas produzem misturas específicas e inusitadas.

Isso é o mesmo que dizer que as palavras afetam e, portanto, têm materialidade. No entanto, sua materialidade é incorporal (FOUCAULT, 2009). Enquanto corpo é atualização, incorporal é virtualidade, na iminência eterna de atualização, fazendo-se variação constante: intervenção no mundo dos corpos que, no entanto, jamais se rende à atualização.

Se um corpo é possível nesse contexto, é o corpo-sem-órgãos, que, de acordo com Deleuze e Guattari (1996), é "matéria intensa e não formada, não estratificada”, "feito de tal maneira que ele só pode ser ocupado, povoado por intensidades” (p. 13), através do qual acontece a expressão “[d]a pura determinação de intensidade, [d]a diferença intensiva” (p. 28) e produz devir.

Afinal, não é à toa chamar acontecimento à produção esquizoradiofônica que emerge dessa sempre tênue linha de um Coletivo que funciona como um corpo-sem-órgãos, onde o que circula só merece o status de intensidade, na medida em que se trata de virtualidades na eterna espera e esquecimento de atualização. Acontecimento que usa dessas intensidades para embaralhar os códigos cronológicos dos trinta minutos de realização do programa. Constitui-se um tempo de material sonoro que consiste e insiste mais do que existe, sob a condição dos afectos que agencia. Marca-se, assim, a tensão entre o limite cronológico dos trinta minutos e seu embaraço, operado pelos imprevistos e improvisos do programa, dando vazão a um tempo outro, rizomático (PELBART, 1998b), imaginário (BLANCHOT, 2005). Chamamos-lhe tempo intensivo, na medida em que aciona "a verdade eterna do tempo: pura forma vazia do tempo, que se liberou 
de seu conteúdo corporal presente” (DELEUZE, 2007, p. 170), sob a ação da virtualidade que dissolve as coisas às intensidades.

O acontecimento esquizoradiofônico opera, então, nessa imprevisibilidade da virtualidade, emaranhando aqueles trinta minutos no ar, ao vivo, onde o devir substitui cronos. Barthes (2008) já provocava acerca da possibilidade da palavra ao vivo funcionar como escrita imediata, sem possibilidade de edição, o que alarga a potencialidade dos encontros inusitados da fala.

Assim, a palavra do Potência Mental dissocia-se do contexto onde se agenciou para lançar-se ao vôo das ondas sonoras. Schafer (2001) cria o conceito de esquizofonia para traduzir a separação que a "invenção do aparelho eletroacústico para a transmissão e estocagem do som” (p. 134) promoveu entre a emissão local de um som e sua propagação em quaisquer outros lugares e quantas vezes se desejasse. Para nós, é algo que diz da ruptura entre a preparação e a realização do programa de rádio. O próprio Schafer (2008) já dizia: “não se pode ver quem ou o quê produz o som: um excitamento invisível para os nervos” (p. 237). A realização torna-se o acontecimento-rádio ainda porque funciona como a duplicação da voz que emanou do espaço das reuniões em direção às ondas sonoras que habitam o vento - e o tempo.

Vento - e tempo - da variação constante, porque intensivos e virtuais. Ampliam a potência da palavra emitida pelo Coletivo porque aumentam seu gradiente de esquizoradiofonia toda vez que a mesma emerge como efeito surpresa diante das determinações da preparação dos programas, encarnando o imprevisto, o improviso e o paradoxo da produção pela anti-produção como constituintes do processo.

Ao acompanhar a produção de estratégias inventivas em tecnologias radiofônicas no campo da saúde mental, atentamos para as intervenções dos loucutores, tecidas por linhas de criação e resistência - intervenções avessas às concepções e representações dominantes que produzem e ampliam preconceitos e reduzem o espaço da diferença.

Ao analisar tais produções como frutos de agenciamento coletivo, visualizam-se as dimensões por onde o desejo corre. Nessa perspectiva, o agenciamento coletivo por uma “comunicação da diferença” remete a um estado de coisas e a estilos de enunciação. Os loucutores, em suas narrativas de vida e, especialmente, em suas experimentações radiofônicas, expressam o que convém e o que não convém, gostos e também desgostos. 
Na próxima seção, apresentamos um recorte do processo de produção e realização de um dos programas de rádio, o qual versou sobre os temas "teatro e prostituição", tendo sido propício à composição de diferentes intercessores. Para apresentá-los, selecionamos dois “acontecimentos", destacando neles imprevistos e improvisos vivenciados pelos loucutores e seus convidados.

\title{
3.1 Primeiro acontecimento: verso e reversos do amor
}

O processo de produção em rádio comunitária, livre, é radicalmente distinto do estabelecido nos meios de comunicação comerciais. Entre as diferenças, observa-se o modo como se constrói a pauta das programações. O Coletivo de Rádio Potência Mental escolhe os assuntos e os modos de apresentá-los nos seus encontros semanais. As temáticas emergem nas conversações entre os loucutores, nutridas com experiências cotidianas narradas e inventadas a cada novo encontro. O seguinte relato de reunião, com a presença de dois novos integrantes, dá-nos algumas pistas do tom dessas conversas:

\begin{abstract}
Após as apresentações falamos sobre sonhos, especialmente aqueles em que se aparece voando. [Um dos loucutores] conta de um sonho em que bate as "asas" sobrevoando a casa dos avós; o [outro] conta de um sonho em que salta de cima das montanhas e, suavemente, toca o solo. Ainda, no assunto de sonhos, falamos da dificuldade em lembrar dos sonhos e [um terceiro loucutor] comentou que bater na cabeça ao acordar provoca esquecimento dos sonhos. Também, falamos sobre gatos; os gatos que tivemos, os destinos que tiveram... Lembrou-se até de um chamado "Nelsinho", de propriedade [de um loucutor] (relato da reunião do dia 03/6/2009)
\end{abstract}

Em meio a essas conversas, um dos loucutores coloca sobre a mesa uma reportagem recortada do jornal, sobre a "rua do sexo" em Porto Alegre, como sugestão de pauta para o próximo programa de rádio. Ao mesmo tempo, um dos novos participantes do grupo conta suas experiências com o teatro, como apreciador e atuador. O tema da prostituição enlaça-se a esse do teatro, pois comenta-se que, em ambos - prostituição e teatro - o que há são personagens. Os fios soltos da conversa encontram, assim, um ponto de amarra na insólita definição do tema que irá ao ar na sexta-feira: teatro e prostituição. Tomamos uma tal associação de idéias - sonhos, gatos, teatro, prostituição - como resultante do agenciamento coletivo de desejo que o espaço daquele encontro 
permite operar, fora da lógica habitual de sentidos. Propõe-se uma visita ao NEP (Núcleo de Estudos em Prostituição) e o contato com a atriz que faz o papel de prostituta na peça “Ópera do Malandro”, com vistas à participação no programa. O encontro com a atriz não acontece de imediato, mas, de forma imprevisível e surpreendente, num trajeto de ônibus, uma participante do Coletivo, em conversa casual com a passageira ao seu lado, descobre que uma das componentes do NEP atua como atriz, inclusive usando o pseudônimo de "atriz-meretriz". Assim, o programa, inicialmente pensado como um debate entre uma prostituta e atuante do NEP e uma atriz que interpretava uma prostituta no teatro terminou desdobrando-se em dois: o primeiro com a presença da atriz-meretriz, o segundo com a participação da atriz da peça.

Ao longo da preparação e execução desse programa, os temas do amor, trabalho, dinheiro, casamento, obsessão, loucura, corpo, sexo, rua, prazer, entre outros, inicialmente propostos em polaridades excludentes, foram aos poucos modulando composições, enlaçando seus termos num “e, e, e, e” rizomático que fazia proliferar os sentidos sobre aquele universo, tornado então polissêmico e plural.

No primeiro programa, com a participação da atriz-meretriz, a conversa entre loucutores e a convidada fluía dando lugar a curiosidade e, ao mesmo tempo, as escolhas de vida que misturam teatro e vida.

Loucutor: (...) eu queria saber uma coisa de ti... amor pela profissão ... É pelo dinheiro... É por tudo, né! Como tu te sente fazendo o papel de meretriz, simplesmente, só o papel de meretriz ... se o cachê vale a pena, a noite, o clima ... como tu te sente?

Atriz-meretriz: Bom, eu não me sinto não no teatro fazendo um papel, mas vivendo uma realidade de uma mulher que simplesmente respeita a profissão que ela aderiu. (transcrição de um trecho do programa de 19 de junho de 2009)

Uma música, que relaciona prostituição, preconceito, denúncia e ironia, foi um dos agenciadores dessa proliferação de sentidos no comunicar potência mental.

Me chamou a atenção a sensibilidade do [loucutor] em achar a música "Geni e o Zeppelin" inapropriada para este programa porque a maior parte da música fala em "joga pedra na Geni", e que por isso não ficaria legal ouvir isso enquanto a [atriz-meretriz] falasse. (Relato da reunião do dia 17/6/09) 
Apesar do alerta feito, a música foi mesmo ao ar. Na seqüência,

Avaliamos que ficou muito desagradável a música ao fundo repetindo "joga pedra na Geni, ela gosta de apanhar, ela é boa de cuspir", tendo em vista as considerações que o [loucutor] havia feito sobre não desrespeitar nossos entrevistados, e também ao fato de que talvez a população que nos escute não entenda a problematização que estamos propondo. (Relato da reunião do dia 24/6/09)

O que a música trazia de controverso foi motivo de preocupação e sua face irônica voltada ao preconceito agenciou sua presença no programa.

De igual modo, “[Um dos loucutores] contou que achou a atriz-meretriz vulgar” (Relato da reunião do dia 24/6/09), ao mesmo tempo em que...

Inesquecível, foi a declaração de amor de [outro loucutor] feita no ar para a atriz-meretriz, um pedido de casamento para o momento em que saíssem da rádio. Chamada de "flor de pessoa" entre outros adjetivos, a atriz-meretriz chegou a ficar meio sem jeito, mas levou na boa, pois era muito bonito o modo como ele fazia isso: um galanteador de primeira linha. (Relato do programa do dia 19/6/09)

Atriz-meretriz, jogapedra-pededesculpas, flor-vulgar. O Coletivo, distraído, pôde honrar a produção que pretende, sustentando o que nela emerge como paradoxos de sentido.

Deleuze e Guattari (1996, p. 24) já davam pistas de como se manter um corpo-semórgãos.

Eis então o que seria necessário fazer: instalar-se sobre um estrato, experimentar as oportunidades que ele nos oferece, buscar aí um lugar favorável, eventuais movimentos de desterritorialização, linhas de fuga possíveis, vivenciá-las, assegurar aqui e ali conjunções de fluxos, experimentar segmento por segmento dos contínuos de intensidades, ter sempre um pequeno pedaço de uma nova terra.

O interesse mantém-se no devir, que Deleuze e Guattari (1995a) já defendiam como a atitude de se deixar afetar pela distância que se tem com o outro, jamais tornar-se o outro. Devir é habitar o sempre entre, é sustentar o paradoxo de seguir em duas ou mais direções ao mesmo tempo. Deleuze e Parnet (1998), assim como Blanchot (2001) já defendiam o entre como a potência maior de uma conversação, uma vez que ele não sustenta paradas, mas sempre linhas, linhas-rizoma. Encontra-se justamente no desnível da diferença a possibilidade de uma conversa entre duas ou mais palavras. O efeito é a emergência de uma palavra plural, escorregadia e fugidia sempre. 
Submetidos a um princípio de descontinuidade e de acaso, o encontro de palavras faz uma virar a outra. Não virar no sentido de tornar-se, mas virar de ponta-cabeça, virar do avesso, virar em qualquer direção, transformá-la em outra coisa que não vai se identificar nem com o primeiro nem com o segundo termo da conversa. Fazer efetivamente o Fora na língua, fazer gaguejar o discurso radiofônico e da comunicação, contaminá-lo com suas virtualidades, multiplicando sempre os efeitos e praticando a resistência.

O devir, com efeito, sustenta-se nesse desvio que nega a todo tempo qualquer identificação, conjurado por uma conversa onde não está colocada a busca de uma síntese que sobreponha as diferenças, mas, antes de tudo, onde elas possam manter-se e onde haja possibilidade de se desviar e acrescentar algo inteiramente novo à relação.

\subsection{Segundo acontecimento: a censura}

Buscar “desculpar” a prostituta por ter entrado "nessa vida” por conta da sua história e das terríveis necessidades pelas quais passou e que a "obrigaram" a "fazer sexo por dinheiro", como se poderia ver nas mídias de massa, não era nossa proposta. Tal como Guattari (2005) pensa as rádios subversivas sob a lógica do rizoma, nossa mídia se propõe menor. Mas a mídia comunitária em que nos inserimos nem sempre acontece como mídia menor, e “[o coordenador da rádio] chamou a atenção para a questão da "censura" (é um programa exibido durante o dia...)” (Relato da reunião do dia 03/6/09).

Boa lembrança, mas... Censura de que mesmo?

Nos assustamos com a má qualidade do início do programa, uma vez que a cortina musical estava com volume mais elevado que as nossas vozes. Discutimos sobre a possibilidade disso ser uma espécie de censura do coordenador da rádio, mas não chegamos a nenhuma conclusão, porque ele pareceu gostar do programa em alguns momentos, mas, em outros, se mostrou tenso e avesso ao tema. (Relato da reunião do dia 24/6/09)

O programa foi muito bom na nossa avaliação e na do coordenador. Ainda que para ele foi um pouco melindroso, pois teve de censurar um excesso da atriz-meretriz ao vivo, dizendo "vocês só vão falar sobre isso?". Isso, no momento em que [uma das loucutoras] [...] perguntou sobre a fantasia na prostituição, semelhante ao teatro ao vir como uma realização. A atrizmeretriz contou de um caso em que o cliente deixou um revolver embaixo do travesseiro no momento da cópula e que gozou ao ver o espanto nos olhos dela. A palavra "gozar" foi censurada [...] No fim do programa, a [ouvinte] 
ligou para o coordenador da rádio, pedindo por que ele não censurou, ou por que censurou, não entendi bem. (Relato do programa do dia 19/6/09)

Má ou boa qualidade? A ouvinte reclamou da censura ou da falta dela? O coordenador da rádio censurou ou não? Ele gostou, ou não? Não está em questão a opinião pessoal do responsável pela rádio comunitária nem as impressões pessoais do relator, mas uma constelação de forças que agem sobre, no, e com o trabalho menor da mídia - forças imprevisíveis, compondo com os resultados e os sentidos produzidos.

A tentativa de decifrar as ações do coordenador dizem da expectativa quanto aos efeitos da nossa intervenção. Matéria impalpável e invisível essa do acontecimento. Maldita ausência de matéria, maldito “não entendi” do sentido. Deleuze (2007) já falava do nãosenso que doa sentido. E a maldição acaba, no instante em que se nota a potência de um mal-entendido.

Bendito mal-entendido. Bendita má-qualidade técnica, que oscila entre ser um imprevisto das vias radiofônicas e um improviso do coordenador diante da surpresa com o tema. Censurou e não censurou, simples assim. Em todo caso, a censura também improvisa e compõe.

Para além de interdição, a censura é mais um e do rizoma do acontecimento. Foucault (2009) já pensava o controle do discurso como processo que compõe a produção discursiva, pois participa das tramas da palavra e mostra mais do que esconde. Aí parece se sustentar uma das menoridades da Rádio Potência Mental: a censura que denuncia a si mesma e, nesse caso, escancara a diferença, afirmado-a, pela dissonância, enquanto alteridade.

Alteridade num encontro que, jamais pacífico, mantém-se em variação, substitui o OU das alternativas pelo E das adições, e o dualismo é substituído pela tensão, pela articulação, pelo paradoxo - afinal, o que somos além de distâncias? O paradoxo é a “paixão do encontro fortuito” segundo Pelbart (1998a, p. 63), a “perturbação irresoluta” que permite ao pensamento pensar o impensável. Isso implica dizer que o encontro de palavras diversas no Potência Mental faz inevitável um paradoxo que, felizmente, jamais se resolve, sustentando o E e a infinita disjunção da palavra.

Essas são as possibilidades do Coletivo aceder ao que Barros (1997) chama de grupodispositivo, a partir do conceito foucaultiano de dispositivo como estratégia processual 
de relações, capaz de, agenciando linhas de força, produzir enunciabilidades, além de visibilidades e subjetivação.

Os paradoxos que fazem funcionar a produção de sentidos na Rádio Potência Mental fazem dela uma Alice. Guattari (2005) já comemorava a insistência de "Milhões e milhões de Alices no ar”, quando o nome Alice era sinônimo de rádio-linha-de-fuga. Com Deleuze (2007), o Potência Mental se aproxima da personagem Alice de Lewis Carroll, confrontada com paradoxos insolúveis que lhe confundem a respeito de sua própria identidade e a carregam por um caminho-sem-caminho que a leva, saindo da profundidade da toca do coelho, a deslizar na superfície do espelho.

\section{4. (In)conclusões}

Os diagnosticados convivem diariamente com diferentes formas de estigmatização que dificultam e enfraquecem as experiências nos espaços coletivos. Ao desejarem romper as fronteiras territoriais e identitárias que tendem a mantê-los confinados, uma vez loucutores, traçam suas intervenções para além dos espaços pré-fixados, constituindo suas próprias redes de conversação presencial e radiofônica.

As intervenções dos loucutores e os acontecimentos que os acompanharam na preparação e realização do programa radiofônico "teatro e prostituição" são considerados como potenciais articuladores das relações de forças inclusivas, entrelaçando desejos, experiências, poderes e saberes, agenciamentos comunicacionais e radiofônicos. Mais do que isso, são importantes intervenções no espaço radiofônico da cidade, rompendo com representações cristalizadas e abrindo caminho à diferença na comunicação.

A experiência do Coletivo de Rádio Potência Mental sugere a emergência de saberes e práticas para a invenção e produção de sentidos de convivência com as diferenças que podem configurar propostas nas áreas de saúde mental e comunicação social desviantes de perspectivas homogeneizantes, fornecendo subsídios para inclusão de tecnologias de informação e comunicação na formulação e implementação de políticas de saúde e comunicação, tendo como perspectiva um alargamento das potências de vida na cidade. 


\section{Bibliográficas}

BARROS, Regina Duarte Benevides de. Dispositivos em ação: o grupo. In: SILVA, André do Eirado et al. (org.). SaúdeLoucura 6. São Paulo: Hucitec, 1997, p. 183-191.

BARTHES, Roland. A escrita do acontecimento. In: MEDITSCH, Eduardo \& ZUCULOTO, Valci (orgs.). Teorias do rádio - textos e contextos. Vol. II. Florianópolis: Insular, 2008, p. 213-218.

BLANCHOT, Maurice. A conversa infinita - a palavra plural. São Paulo: Escuta, 2001.

BLANCHOT, Maurice. O livro por vir. São Paulo: Martins Fontes, 2005.

CAIAFA, Janice. Comunicação da diferença. Revista Fronteiras. Estudos midíaticos, São Leopoldo - RS, v. 7, n. 1, p. 47-56, 2005.

CECCHIN, Ricardo Andre. Loucutores da potência mental: de acompanhantes e acompanhados a radialistas. Trabalho apresentado no 9 ${ }^{\circ}$. Salão de Extensão da UFRGS. Porto Alegre, setembro de 2008.

COGO, Denise Maria. Mídias, identidades culturais e cidadania: sobre cenários e políticas de visibilidade midiática dos movimentos sociais. In: PERUZZO, Cicilia M. Krohling. (Org). Vozes cidadãs - Aspectos teóricos e análises de experiências de comunicação popular e sindical na América Latina. São Paulo: 2004.

DELEUZE, Gilles. A Lógica do Sentido. São Paulo: Perspectiva, 2007.

DELEUZE, Gilles \& GUATTARI, Félix. Capitalismo e esquizofrenia. In: DELEUZE, Gilles. A ilha deserta: e outros textos. São Paulo: Iluminuras, 2006, p. 295-305.

Mil Platôs II Capitalismo e Esquizofrenia. Rio de Janeiro: Editora 34, 1995.

Mil Platôs III Capitalismo e Esquizofrenia. Rio de Janeiro: Editora 34, 1996.

O Anti-Édipo: capitalismo e esquizofrenia 1. Lisboa: Assírio Alvim,2004.

DELEUZE, Gilles \& PARNET, Claire. Diálogos. São Paulo: Editora Escuta, 1998.

FOUCAULT, Michel. A Ordem do Discurso - L’Ordre Du Discours, Leçon inaugurale ao Collège de France prononcée le 2 décembre 1970. 18. Ed. São Paulo: Edições Loyola, 2009.

GUATTARI, Félix. Caosmose: um novo paradigma estético. São Paulo: Editora 34, 1992.

Milhões e milhões de Alices no ar. In: MEDITSCH, Eduardo (org.). Teorias do rádio - textos e contextos. Vol. I. Florianópolis: Insular, 2005, p. 199-207. 
LEVY, Pierre. As tecnologias da inteligência; tradução Carlos Irineu da Costa. Rio de Janeiro. Ed. 34. 1993.

PALOMBINI, Analice de Lima; CABRAL, Karol Veiga \& BELLOC, Márcio Mariath. Dispositivos Clínicos em Saúde Mental: a clínica na cidade entre o acontecimento e a permanência - Do AT à radiodifusão como estratégia de ocupação da cidade. III Congresso Internacional de Psicopatologia Fundamental, Niterói, Rio de Janeiro, 2008.

PELBART, Peter Pál. O tempo não-reconciliado. São Paulo: Perspectiva: FAPESP, 1998a.

PELBART, Peter Pál. Rizoma Temporal. Educação, Subjetividade e Poder, Porto Alegre, v. 5, n. 5, p. 60-63, jul. 1998b.

RAJCHMAN, John. Lógica do sentido, ética do acontecimento. In: ESCOBAR, Carlos Henrique (org.) Dossiê Deleuze. Rio de Janeiro: Hólon Editorial, 1991, p.56-61.

SCHAFER, R. Murray. A afinação do mundo: uma exploração pioneira pela história passada e pelo atual estado do mais negligenciado aspecto do nosso ambiente: a paisagem sonora. São Paulo: Editora UNESP, 2001.

SCHAFER, R. Murray. Rádio Radical e a Nova Paisagem Sonora. In: MEDITSCH, Eduardo \& ZUCULOTO, Valci (orgs.). Teorias do rádio - textos e contextos. Vol. II. Florianópolis: Insular, 2008, p. 237-250.

TIBULO, Ana Paula; ROOS, Cristine Moraes; NUNES, Deise Cardoso; MACHADO Greice Andréa Barbosa; TEIXEIRA, Ivana dos Santos; DAL MOLIN, Jacqueline Picoral; GARCIA, Simone Sá Britto; TERRAGNO, Tatiana Martins; SILVA, Tatiane Patrícia Souza da. Programa de Rádio Potência Mental busca seu espaço. Trabalho apresentado no V Congresso Internacional de Salud Mental e Derechos Humanos. Buenos Aires, 2006. 